ARTICLE

\title{
Precise spatiotemporal control of voltage-gated sodium channels by photocaged saxitoxin
}

\author{
Anna V. Elleman ${ }^{1}$, Gabrielle Devienne (10 2 ${ }^{2}$ Christopher D. Makinson (10 2,3,4, Allison L. Haynes ${ }^{1}$, \\ John R. Huguenard (id ${ }^{2 凶} \&$ J. Du Bois (i) ${ }^{1 凶}$
}

Here we report the pharmacologic blockade of voltage-gated sodium ion channels ( $\mathrm{Navs}$ ) by a synthetic saxitoxin derivative affixed to a photocleavable protecting group. We demonstrate that a functionalized saxitoxin (STX-eac) enables exquisite spatiotemporal control of Navs to interrupt action potentials in dissociated neurons and nerve fiber bundles. The photo-uncaged inhibitor (STX-ea) is a nanomolar potent, reversible binder of Navs. We use STX-eac to reveal differential susceptibility of myelinated and unmyelinated axons in the corpus callosum to $\mathrm{Na}_{\mathrm{v}}$-dependent alterations in action potential propagation, with unmyelinated axons preferentially showing reduced action potential fidelity under conditions of partial Nav block. These results validate STX-eac as a high precision tool for robust photocontrol of neuronal excitability and action potential generation.

\footnotetext{
${ }^{1}$ Department of Chemistry, Stanford University, Stanford, CA, USA. ${ }^{2}$ Department of Neurology \& Neurological Sciences, Stanford University School of Medicine, Stanford, CA, USA. ${ }^{3}$ Institute for Genomic Medicine, Columbia University Irving Medical Center, New York, NY, USA. ${ }^{4}$ Department of Neurology, Columbia University Irving Medical Center, New York, NY, USA. ${ }^{凶}$ email: huguenar@stanford.edu; jdubois@stanford.edu
} 
S mall molecules bearing photocleavable protecting groups ${ }^{1}$ have been used extensively to manipulate biochemical processes, including protein binding interactions ${ }^{2-4}$, receptor activation ${ }^{5}$, and signaling pathway dynamics ${ }^{6,7}$. Photocaged molecules provide unique advantages over traditional pharmacologic agents and pro-drugs, namely precise temporal and spatial release, tunability, and reagentless deprotection. Neuroactive compounds including $\mathrm{GABA}^{8}$, glutamic $\operatorname{acid}^{9,10}$, dopamine $^{11}$, serotonin ${ }^{12}$, Leu-enkephalin ${ }^{13}$, cAMP $^{14}$, lipids ${ }^{15}, 4$ aminopyridine ${ }^{16-18}$, and calcium ${ }^{19}$ have been caged in order to study signaling mechanisms in cells, tissues, and whole organisms. Despite this impressive collection of photo-protected reagents, to our knowledge, no such compound has been designed to directly target action potential (AP) initiation in electrically excitable cells. Herein, we demonstrate that photochemical release of a caged form of saxitoxin (STX-eac) impedes AP initiation and propagation by blocking voltage-gated sodium ion channel $\left(\mathrm{Na}_{\mathrm{V}}\right)$ function. Experiments with dissociated neuronal cells and in tissue slice validate the utility of this unique tool compound for studies of electrical signaling.

Modern methods in neuroscience enable precise optical and chemical control of neuronal activity. Viral transduction of optogenetic and chemogenetic ion channels and receptors makes possible specific activation or inactivation of defined cell populations ${ }^{20-23}$. These technologies are neuromodulating (i.e., the likelihood of signaling is increased or decreased) and generally do not completely silence neuronal outputs ${ }^{24,25}$. $\mathrm{Na}_{V}$ s are responsible for mediating AP initiation and propagation and are therefore an ideal target for controlling electrical transmission. Furthermore, the location, amplitude, frequency, and timing of sodium ion influx are important factors that determine electrical excitability, synaptic release, and ultimately information flow through neural systems ${ }^{26,27}$.

In addition to affecting AP properties, a growing body of evidence implicates $\mathrm{Na}_{V}$ activity in modulating dendritic currents, synaptic release, homeostasis, circuit function, and ultimately, behavior $^{28}$. Studies of $\mathrm{Na}_{\mathrm{V}}$ physiology have primarily relied on the pharmacological blockade of axon excitability using partially inactivating concentrations $s^{29,30}$ or local pressure puffing of smallmolecule inhibitors ${ }^{31,32}$; however, these methods do not provide the fine spatial or temporal resolution required to specifically inactivate selected cells or $\mathrm{Na}_{V} s$ in cellular compartments. The design and development of photocaged $\mathrm{Na}_{\mathrm{V}}$ inhibitors for precise control of neuronal membrane excitability address these limitations.

\section{Results}

Synthesis of photocaged STX derivatives. In order to achieve spatiotemporal control of $\mathrm{Na}_{V} s$, a photocaging group was appended to a synthetic derivative of saxitoxin (STX), a naturally occurring bis-guanidinium toxin that specifically inhibits the action of six of nine $\mathrm{Na}_{\mathrm{V}}$ subtypes (e.g., $\mathrm{IC}_{50}=1.2 \mathrm{nM}$ vs. rat $\mathrm{Na}_{\mathrm{V}}$ $1.2)^{33}$. STX targets the outer mouth of the $\mathrm{Na}_{\mathrm{V}}$ pore, thereby occluding ion passage into cells. The location of the STX-binding site enables extracellular application, and block by this smallmolecule toxin is entirely reversible. Modification of the N21 carbamate of STX affords saxitoxin ethylamine (STX-ea 1) ${ }^{34}$, a toxin derivative of similar potency to that of the natural product $\left(\mathrm{IC}_{50}=14.4 \mathrm{nM}\right.$ vs. rat $\left.\mathrm{Na}_{\mathrm{V}} 1.2\right)$. Like STX, STX-ea 1 is a reversible pore blocker that exerts no effect on $\mathrm{Na}_{\mathrm{V}}$ voltagedependence of activation or inactivation (Supplementary Fig. 1a-c). Different prosthetic groups, including photolabile carbamate derivatives, can be attached to the primary amine in STX-ea through selective acylation reactions. This tactic allows for the introduction of the photocage in the final step of the synthetic sequence and is considerably more efficient than the protection of either or both of the guanidinium groups. We exploited this chemistry to access four coumarin-derived photocaged STXs, including STX-eac 5 (Fig. 1).

Coumarin photo-protecting groups are well-established and display excellent one- and two-photon uncaging efficiencies ${ }^{35,36}$. In addition, the byproducts of uncaging are generally inert to biological tissue ${ }^{37}$. Based on models of STX binding to the channel pore and structure-activity studies of toxin binding ${ }^{38,39}$, we speculated that attachment of a sterically large, anionic photoprotecting group to STX-ea 1 would significantly destabilize toxin binding. The outer mouth of the channel funnels to the selectivity filter (the narrowest region of the ion permeation pathway), and STX is tightly lodged in this receptor site ${ }^{38}$. In addition, multiple aspartate and glutamate groups surround the toxin. Accordingly, conjugation of two different anionically charged coumarin protecting groups, 6-bromo-7-hydroxy-4-(hydroxymethyl)coumarin $\left(\mathrm{pK}_{\mathrm{a}}=6.2, \quad \lambda_{\max } \sim 375 \mathrm{~nm}\right)^{40-42}$ and 7-bis(carboxymethyl)-4-(hydroxymethyl)coumarin $\left(\lambda_{\max } \sim 380 \mathrm{~nm}\right)^{35,43}$, to $\mathbf{1}$ were prioritized, yielding compounds 3 and $\mathbf{5}$, respectively. Two additional coumarin derivatives, 2 and 4, were prepared for comparative purposes and to better understand the requisite structural modifications that destabilize the binding of the photocaged toxin to $\mathrm{Na}_{\mathrm{V}}{ }^{44,45}$.

Validation of photocaged STX derivatives. All photo-protected STXs were evaluated for binding affinity by whole-cell electrophysiology against Chinese hamster ovary (CHO) cells stably expressing $\mathrm{rNa}_{\mathrm{V}}$ 1.2. Compounds $\mathbf{2 - 5}$ were up to 70 times less potent than STX-ea 1, with $\mathbf{5}$ displaying the highest $\mathrm{IC}_{50}$ value of $>1 \mu \mathrm{M}$ (Fig. 2a). As predicted, photocaged STXs bearing anionic groups are less potent than their uncharged

a

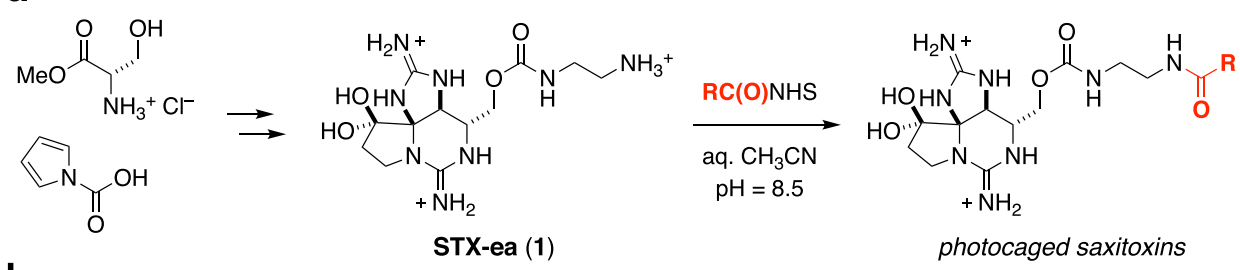

b<smiles>COc1cc2oc(=O)cc(COCC(C)C)c2cc1Br</smiles>

2<smiles>COCc1cc(=O)oc2cc([O-])c(Br)cc12</smiles>

3<smiles>CCCOCc1cc(=O)oc2cc(N(CC(=O)OCC)CC(=O)OCC)ccc12</smiles>

4

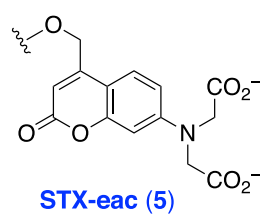

Fig. 1 Caging STX-ea 1 with photo-protecting groups. a Synthesis and selective carbamoylation of STX-ea 1. b Photocaged derivatives of STX-ea. 
a

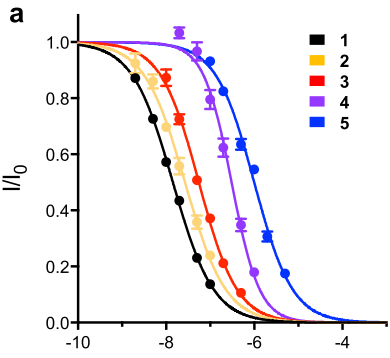

$\log [$ Concentration], M

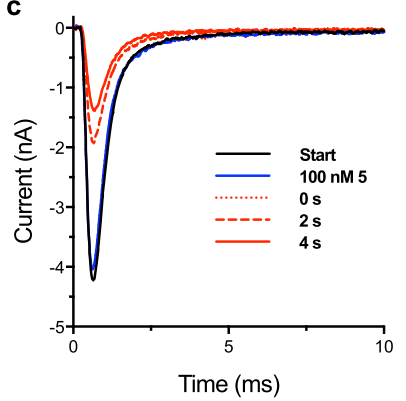

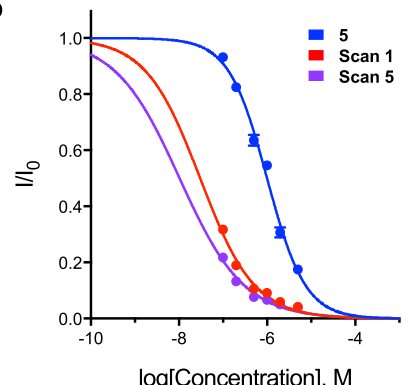

d

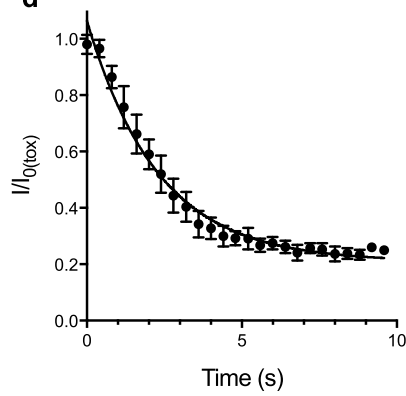

Fig. 2 Photochemical release of STX-ea 1 results in a block of $\mathrm{Na}_{\mathbf{v}} \mathbf{1 . 2}$

CHO. a Electrophysiological characterization of photocaged STXs against Nav1.2 CHO. $I_{50}$, Hill coefficients: $1=14.4 \pm 0.3 \mathrm{nM},-0.94 \pm 0.02 ; \mathbf{2}=$ $27.0 \pm 1.4 \mathrm{nM},-0.94 \pm 0.05 ; \mathbf{3}=55.5 \pm 2.1 \mathrm{nM},-1.01 \pm 0.04 ; \mathbf{4}=307.5 \pm$ $16.6 \mathrm{nM},-1.37 \pm 0.09 ; \mathbf{5}=1003.8 \pm 42.2 \mathrm{nM},-1.00 \pm 0.04$. Data represent mean \pm s.e.m. (for compound $\mathbf{1}[2,5,10 \mathrm{nM}], n=6,[20,50,100 \mathrm{nM}], n=$ $7 ; \mathbf{2}, n=3 ; \mathbf{3}, n=6 ; \mathbf{4}, n=6 ; \mathbf{5}, n=5)$. b Electrophysiological

characterization and laser uncaging of $\mathbf{5}$ against $\mathrm{Nav} 1.2 \mathrm{CHO}$. Initial IC 50 in blue; apparent $\mathrm{IC}_{50}$ following laser scan 1 in red $(30.4 \pm 3.6 \mathrm{nM})$ and after laser scan 5 in purple $(10.4 \pm 2.0 \mathrm{nM})$. Data represent mean \pm s.e.m. $(n=$ 5). c Representative trace depicting uncaging of $100 \mathrm{nM} \mathbf{5}$ against Nav1.2 CHO. Traces collected in the order: Start, $100 \mathrm{nM} \mathrm{5,} 0$ s, 2 s, 4 s. Laser applied immediately prior to $10 \mathrm{~ms}, 0 \mathrm{mV}$ voltage step (trace $0 \mathrm{~s}$ ). d Time course of uncaging of $100 \mathrm{nM} 5$ against Nav1.2 CHO pulsed from $-100 \mathrm{mV}$ to $0 \mathrm{mV}$ at $2.5 \mathrm{~Hz}$. The laser was applied at $t=0 \mathrm{~s}$. Data were subjected to exponential regression yielding $\tau=2.3 \pm 0.2 \mathrm{~s}$ (half-life $1.6 \pm 0.1 \mathrm{~s}$ ), $R^{2}=$ 0.9056. Data represent mean \pm s.e.m. $(n=4) . n=$ number of biologically independent cells.

counterparts $\left(\mathrm{IC}_{50}: \mathbf{2}=27 \mathrm{nM}\right.$ vs. $\mathbf{4}=56 \mathrm{nM} ; \mathbf{3}=308 \mathrm{nM}$ vs $\mathbf{5}=1.004 \mu \mathrm{M})$. Similarly, increasing steric bulk also impairs toxin binding ( $c f .4$ and $\mathbf{5}$ vs $\mathbf{2}$ and $\mathbf{3}$ ).

In order to evaluate the uncaging efficiencies of photocaged STXs, voltage-clamped $\mathrm{Na}_{\mathrm{V}} 1.2 \mathrm{CHO}$ cells bathed in reagent were pulsed with $355 \mathrm{~nm}$ light $(5 \times 5 \mathrm{~ms})$ while monitoring changes in channel block (Fig. 2b and Supplementary Fig. 2). STX-eac 5 exhibited the highest uncaging efficiency, as measured by comparing the change in $\mathrm{IC}_{50}$ of the caged compound against the apparent $\mathrm{IC}_{50}$ following light exposure. For 5, 5 $\times 5 \mathrm{~ms}$ of light exposure was highly effective at removing the coumarin group (5=1.004 $\mu \mathrm{M}$ vs. $10 \mathrm{nM}$ post uncaging). By comparison, compounds 2, 3, and 4 displayed $\leq 3$-fold change in $\mathrm{IC}_{50}$ under these same conditions. Control experiments on cells treated with STX-ea 1 and subjected to UV light showed no laser-dependent changes in $\mathrm{Na}_{\mathrm{V}}$ activity (Supplementary Fig. 1d-f).

Following light exposure, all coumarin-modified STXs uncage and achieve maximal block of $\mathrm{Na}_{\mathrm{V}} 1.2$ within $\sim 4 \mathrm{~s}$. Time-course experiments with the most promising photocaged toxin, 5, revealed a time constant for exponential current decay of $2.3 \pm$ $0.2 \mathrm{~s}$ (i.e., half-maximal block achieved within $1.6 \pm 0.1 \mathrm{~s}$; Fig. $2 \mathrm{c}$, d). The rapid time constant for block by the uncaged product, STX-ea $\mathbf{1}$, is consistent with the measured association constant of

this inhibitor $\left(\mathrm{k}_{\mathrm{on}}=11.0 \pm 0.7 \times 10^{6} \mathrm{M}^{-1} \mathrm{~s}^{-1}\right)$, which is similar to STX itself (Supplementary Fig. 1g, h). As noted for STX, 1 rapidly dissociates from the channel pore upon perfusion of cells with buffer solution $\left(\mathrm{k}_{\mathrm{off}}=3.8 \pm 0.1 \times 10^{2} \mathrm{~s}^{-1}\right)$.

Interruption of action potential (AP) trains in primary neurons. To assess the utility of photocaged STX-ea to block APs, STX-eac 5 was evaluated against cultured rat embryonic hippocampal neurons (E18). In order to preserve cell health, laser excitation at $355 \mathrm{~nm}$ was limited to a $1 \times 5 \mathrm{~ms}$ pulse. Against $\mathrm{Na}_{\mathrm{V}} \mathrm{s}$ in primary neurons, the $\mathrm{IC}_{50}$ value for 5 was determined to be $2.15 \pm 0.21 \mu \mathrm{M}$. The twofold larger $\mathrm{IC}_{50}$ value compared to that obtained against $\mathrm{Na}_{\mathrm{V}} 1.2$ in $\mathrm{CHO}$ cells may be due to the presence of multiple STX-sensitive $\mathrm{Na}_{V}$ isoforms $(1.1-1.3,1.6)^{46}$ against which the potency of $\mathbf{5}$ is slightly varied (Supplementary Fig. 3) or from the co-expression of $\beta$-auxiliary proteins (and/or other accessory proteins) in hippocampal neurons ${ }^{27}$. Analogous to experiments using $\mathrm{CHO}$ cells, the uncaging efficiency of $\mathbf{5}$ is high, as the apparent $\mathrm{IC}_{50}$ drops from $2.1 \mu \mathrm{M}$ to $106 \mathrm{nM}$ following a single $5 \mathrm{~ms}$ laser pulse (Fig. 3a, b). Maximum channel inhibition is achieved after $2 \mathrm{~s}$ with a time constant of $\sim 1 \mathrm{~s}$ (Supplementary Fig. 4a).

Given the effectiveness of $\mathbf{5}$ for inhibiting $\mathrm{Na}_{\mathrm{V}}$ activity in hippocampal neurons, we next tested the ability of this reagent to impede action potential (AP) trains. Current-clamped dissociated neurons were bathed in varying concentrations of $\mathbf{5}$ to monitor the effects on AP firing frequency (Supplementary Figs. 5-7). Notably, at 100-200 nM concentration, 5 has no influence on AP firing rate, despite blocking $\sim 5-10 \%$ of the total population of $\mathrm{Na}_{V}$ s (Fig. 3c). Subsequent uncaging, particularly in experiments using $200 \mathrm{nM} \mathrm{5,} \mathrm{dramatically} \mathrm{reduced} \mathrm{spike} \mathrm{frequency,} \mathrm{on} \mathrm{a}$ timescale consistent with voltage-clamp recordings $(\tau \sim 1.1 \mathrm{~s}$; Supplementary Fig. 4b). Analysis of both voltage- and currentclamp data from hippocampal neurons indicates that $\geq 75 \%$ channel block is needed to completely eliminate AP trains (Fig. 3c), consistent with previous reports ${ }^{47,48}$. Notably, blocking $\sim 10-25 \%$ of $\mathrm{Na}_{\mathrm{V}} \mathrm{s}$ resulted in the steepest decline in AP firing rate. Thus, it is possible to vary the concentration of $\mathbf{5}$, laser power, and/or exposure time to alter AP frequency. For example, $200 \mathrm{nM} 5$ subjected to a single $5 \mathrm{~ms}$ laser pulse produced a six-fold increase in $\mathrm{Na}_{\mathrm{V}}$ block-from 10 to $60 \%$ inhibition pre- to post uncaging-the difference between complete maintenance of AP firing and reduction to $11.6 \pm 2.9 \%$ of initial frequency, with over $40 \%$ of cells incapable of initiating a single action potential (Fig. 4a, b). AP block extends upward of $15 \mathrm{~s}$, and is completely reversible upon perfusing cells with buffer (Fig. 4c and Supplementary Figs. 4-7). These data demonstrate that uncaging of $\mathbf{5}$ functions as a molecular circuit breaker to rapidly block trains of APs.

Effect of STX-eac in a corpus callosum slice preparation. To evaluate the functional effect of STX-eac 5 on axons, we performed electrophysiological analyses of compound action potentials (CAPs) evoked in the corpus callosum (Fig. 5a). CAPs have been previously characterized in the mouse corpus callosum as a biphasic response with an early component (1-2 ms latency) representing mainly fast and large myelinated axons (N1) and a later component (3-6ms latency) representing slower unmyelinated axons (N2) ${ }^{49-51}$ (Fig. 5b). Previous studies of callosal signaling have been conducted at room temperature to slow down transmission speed in order to improve $\mathrm{N} 1$ detection $^{51}$; our experiments were performed at $34^{\circ} \mathrm{C}$ to more closely match physiological conditions. To improve detection of $\mathrm{N} 1$ and $\mathrm{N} 2$, we estimated current-source density (CSD, see "Methods" section), which represents the inflow of $\mathrm{Na}^{+}$into axons during the 
a
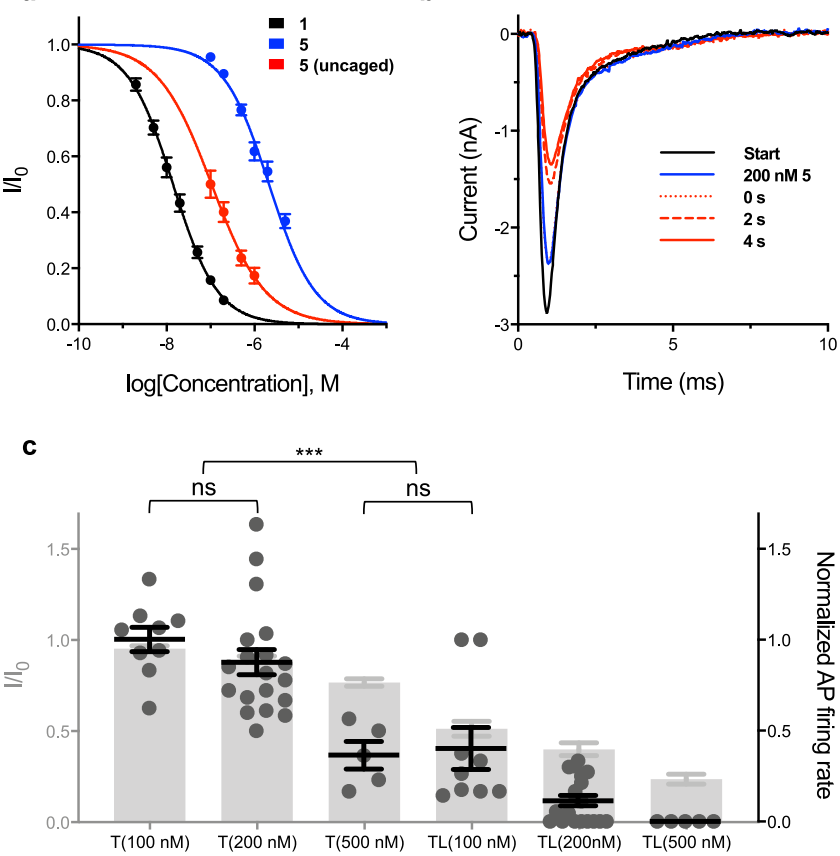

Fig. 3 Uncaging of STX-eac 5 results in fast, concentration-dependent $\mathrm{Na}_{\mathbf{v}}$ block and inhibition of APs. a Electrophysiological characterization of photocaged STXs against hippocampal neurons DIV 6-8. IC $\mathrm{C}_{50} \mathrm{~S}$, Hill Coefficients: $\mathbf{1}=14.1 \pm 0.8 \mathrm{nM},-0.86 \pm 0.04$; STX-eac $\mathbf{5}=2148.4 \pm 209.9 \mathrm{nM}$, $-0.83 \pm 0.07$. Apparent $I C_{50}$, Hill Coefficient: 5 (uncaged) $=106.0 \pm 17.4 \mathrm{nM}$, $-0.71 \pm 0.11$. Data represent mean \pm s.e.m. (for compound $\mathbf{1}[2 \mathrm{nM}], n=4$; [5, $10,20,50,100 \mathrm{nM}], n=5$. For compound $\mathbf{5}[100 \mathrm{nM}], n=12 ;[200 \mathrm{nM}], n=$ 10; [500 nM], $n=13 ;[1 \mu \mathrm{M}], n=12 ;[2 \mu \mathrm{M}, 5 \mu \mathrm{M}], n=4$. For compound $\mathbf{5}$ (uncaged) $[100 \mathrm{nM}], n=4 ;[200 \mathrm{nM}], n=6$; [500 nM], $n=5 ;[1 \mu \mathrm{M}], n=$ 4.). b Representative trace depicting uncaging of $200 \mathrm{nM} 5$ against hippocampal neurons DIV 6-8. Traces collected in the order: Start, 200 nM 5, $0 \mathrm{~s}, 2 \mathrm{~s}, 4 \mathrm{~s}$. Laser applied immediately prior to $10 \mathrm{~ms}, 0 \mathrm{mV}$ voltage step (trace 0 s). c Comparison between current-clamp (DIV 9-13, right axis, black) and voltage-clamp (DIV 6-8, left axis, gray) data collected pre- and post-uncaging at various concentrations of $\mathbf{5}$. $\mathrm{T}$, toxin applied; TL, toxin and laser applied. Statistics calculated for current-clamp data. ns $P>0.5$, ${ }^{\star \star \star} P<0.001$, one-way ANOVA with Tukey's correction, mean \pm s.e.m. T(100 nM) vs. T(200 nM), $P$ $=0.7727 ; \mathrm{T}(100 \mathrm{nM})$ vs. $\mathrm{T}(500 \mathrm{nM}), P=1.34 \times 10^{-4} ; \mathrm{T}(200 \mathrm{nM})$ vs. $\mathrm{T}(500$ $\mathrm{nM}), P=8.46 \times 10^{-4} ; \mathrm{T}(500 \mathrm{nM})$ vs. $\mathrm{TL}(100 \mathrm{nM}), P=0.9997$. (For $\mathrm{T}(100$ $\mathrm{nM}), n=9 ; \mathrm{T}(200 \mathrm{nM}), n=19 ; \mathrm{T}(500 \mathrm{nM}), n=5 ; \mathrm{TL}(100 \mathrm{nM}), n=9 ; \mathrm{TL}$ (200 nM), $n=19 ; \mathrm{TL}(500 \mathrm{nM}), n=5$.) $n=$ number of biologically independent cells.

compound action potential. The first and second anti-peaks of the extracted CSD were used to determine the amplitude and timing of N1 and N2 action potential signals. This method of analysis was more accurate than measuring peak fiber volley in the local field potential (LFP) itself, as the latter was partially obscured by the electrical stimulus artifact. Examples of LFP and corresponding CSD traces are shown for $250 \mathrm{nM}$ and $500 \mathrm{nM}$ concentrations of 5 (Fig. 5c). The amplitudes and timing of N1 and $\mathrm{N} 2$ peaks were determined for channels closest to the stimulating electrode.

In order to uncage 5 , an optical fiber was placed close to the stimulating electrode, in contact with the upper surface of the slice, to deliver UV light (Fig. 5a). For each slice, we determined that exposure to UV light itself had a negligible effect on electrophysiological responses (Supplementary Fig. 8). Quantitative analysis of peak amplitude and frequency revealed that the two CAP components, N1 and N2, are differentially affected by uncaging 5 . By design, 5 was focally uncaged along the path of the callosal fibers between the site of initiation in the lateral corpus callosum, and propagation was measured along the midline. Uncaging of $250 \mathrm{nM}$ and $500 \mathrm{nM} 5$ produced N1 CAP amplitude decreases of $23 \%$ and $37 \%$, respectively (Supplementary Table 1 ). $\mathrm{N} 2$ was more sensitive to uncaged $\mathbf{5}$, with $\mathrm{N} 2$ peak sink amplitude reduced at all three concentrations of this compound-25\% at $100 \mathrm{nM}, 36 \%$ at $250 \mathrm{nM}$, and $58 \%$ at $500 \mathrm{nM}$ (Fig. 5d and Supplementary Table 1). These results indicate that transmission in unmyelinated callosal axons is more susceptible to partial sodium channel block than in myelinated fibers.

Our protocol for uncaging of $\mathbf{5}$ near the stimulation site revealed that callosal transmission speed (away from the uncaging location) along the midline is relatively insensitive to $\mathrm{Na}_{\mathrm{V}}$ block; however, the arrival time of the CAP at the recording electrode is delayed, especially for the N2 component. Peak latency for N1 was only affected after uncaging the highest concentration of $\mathbf{5}$, $500 \mathrm{nM}$, slowing by $0.28 \mathrm{~ms}$. These results contrast rather starkly recordings of N2, which show a delayed peak response of $\sim 0.2 \mathrm{~ms}$ with $100 \mathrm{nM}$ or $250 \mathrm{nM} \mathrm{5}$, and suggest a slowed CAP conduction that is restricted to the portion of axons near the site of uncaging. The effect of uncaging $500 \mathrm{nM} 5$ on N2 CAP peak onset could not be reliably determined, as the signal is undetectable in $30 \%$ of these measurements (Fig. 5c, e and Supplementary Table 1). Although signal arrival time of the CAP at the callosal midline was reduced by uncaged $\mathbf{5}$, callosal fiber velocity, as estimated by the peak latency recorded along the midline of the callosum, was largely unaffected (Supplementary Fig. 9 and Supplementary Table 1).

Our findings demonstrate that focally uncaging $\mathbf{5}$ enables studies of action potential initiation and propagation, and that this tool compound could be particularly useful for modulating CAPs in unmyelinated axons. We wondered, however, if the differential effect of focally uncaged 5 on N1 vs. N2 might be due to an underlying sensitivity in the $\mathrm{Na}_{\mathrm{V}} \mathrm{s}$ responsible for action potential initiation or propagation in myelinated vs. unmyelinated fibers. To address this possibility, we tested the sensitivity of $\mathrm{N} 1$ and N2 to global, steady-state (i.e., bath) application of the active parent compound, STX-ea 1. Quantitative analysis of peak amplitude (Fig. 5d) and onset (Fig. 5e) revealed that N1 and N2 are similarly affected by bath application of $100 \mathrm{nM} \mathrm{1,} \mathrm{which}$ decreases N1 and N2 CAP amplitudes by 26\% (Supplementary Table 2). In addition, bath application of $\mathbf{1}$ consistently affects callosal propagation speed, with a delayed peak response at the nearest electrode of both $\mathrm{N} 1$ and N2 CAP by $\sim 0.1 \mathrm{~ms}$ each. In contrast with targeted sodium channel inhibition by photouncaging 5, CAP velocity is significantly slowed for both $\mathrm{N} 1$ and $\mathrm{N} 2$ with bath application of 1 : from $1.36 \pm 0.16 \mathrm{~m} / \mathrm{s}$ to $1.00 \pm 0.08$ $\mathrm{m} / \mathrm{s}$ for $\mathrm{N} 1$, and from $0.53 \pm 0.01 \mathrm{~m} / \mathrm{s}$ to $0.43 \pm 0.03 \mathrm{~m} / \mathrm{s}$ for $\mathrm{N} 2$ (Supplementary Table 2).

\section{Discussion}

STX-eac 5 is a high-precision molecular tool capable of spatiotemporal inhibition of $\mathrm{Na}_{V}$ s to block the transmission of action potentials. Application of $\mathbf{5}$ to primary neuronal cells and tissue does not alter endogenous electrical signaling. Focal uncaging drives rapid release of STX-ea $\mathbf{1}$, which achieves maximal $\mathrm{Na}_{V}$ inhibition within $2 \mathrm{~s}$ following laser excitation. The percent of $\mathrm{Na}_{\mathrm{V}}$ block can be regulated by attenuating the laser power and duration of light exposure in addition to the concentration of $\mathbf{5}$. We have demonstrated that $\mathbf{5}$ is well tolerated by cells for prolonged periods of time and that the effects of uncaging are fully reversible, with peak sodium currents restored upon perfusion of cells or tissue slice with buffer solution.

In cultured hippocampal neurons and in brain slice, 5 functions as a reversible molecular switch on AP generation. Due to 


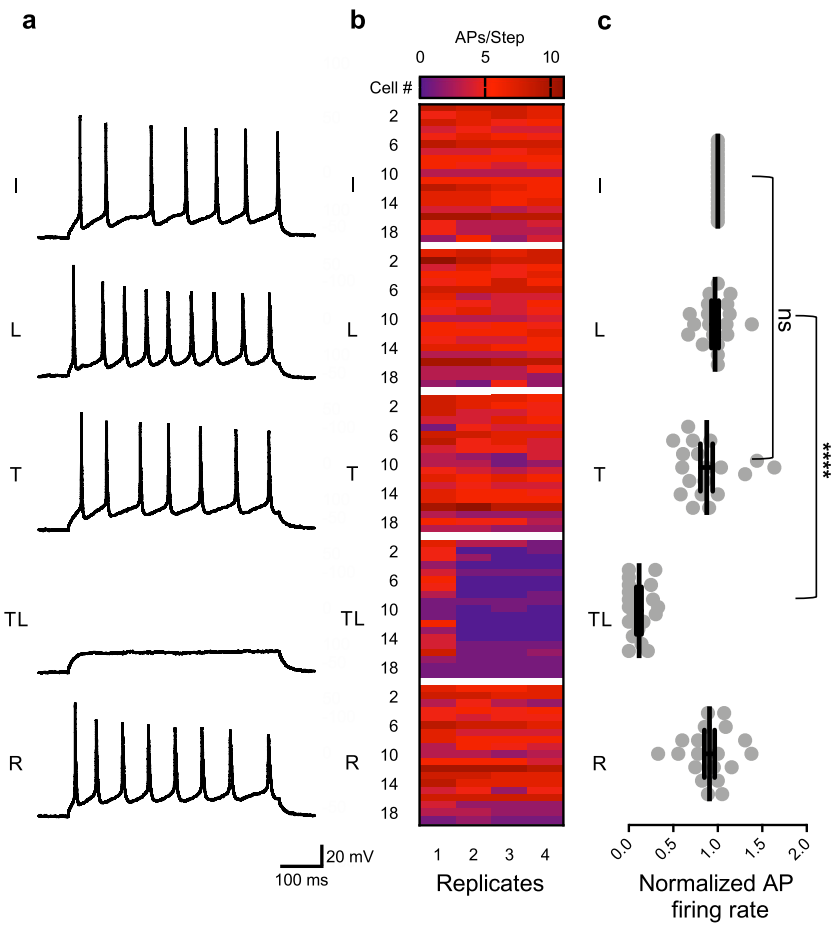

Fig. 4 Uncaging of $200 \mathrm{nM}$ STX-eac 5 shows reversible inhibition of AP firing. a Representative traces depicting initial (I), laser applied (L), $200 \mathrm{nM}$ toxin $\mathbf{5}$ applied (T), $200 \mathrm{nM}$ toxin $\mathbf{5}$ and laser applied (TL), and recovered (R) after wash-off AP trains evoked by $500 \mathrm{~ms}, 50-150 \mathrm{pA}$ current injections into hippocampal neurons DIV 9-13. Data taken from replicate current step 2 vis-à-vis (b). b Heatmap summary of data described in a color-coded by the number of action potentials per step (four replicate current steps at $0.25 \mathrm{~Hz}$ per condition, $n=19)$. c Equilibrated normalized action potential firing rate (i.e., over current steps 2-4) pre- and post-laser induced uncaging of 5. ns $P>0.5$, ${ }^{\star \star \star \star} P<0.0001$, one-way ANOVA with Tukey's correction, mean \pm s.e.m. I vs. L, $P=0.9503$; I vs. T, $P=0.4131$; L vs. T, $P=0.7437 ;$ I vs. TL, $P=2.7 \times 10^{-14}$; L vs. TL, $P=9.69 \times 10^{-12}$; T vs. $\mathrm{TL}, P=2.38 \times 10^{-8} .(n=19) . n=$ number of biologically independent cells.

the large potency difference between $5\left(\mathrm{IC}_{50}=2.1 \mu \mathrm{M}\right)$ and the uncaged compound, $\mathbf{1}\left(\mathrm{IC}_{50}=14 \mathrm{nM}\right)$, complete block of evoked AP trains can be achieved following light exposure. As STXsensitive $\mathrm{Na}_{V}$ isoforms are preponderant in CNS tissue ${ }^{52}$, we anticipate that STX-eac $\mathbf{5}$ will be a valuable tool for examining $\mathrm{Na}_{\mathrm{V}}$ activity across a broad range of cell types. Moreover, given the choice of a coumarin photo-protecting group and the reported two-photon cross-sectional efficiency of uncaging such molecules $\left(\delta_{\text {unc }}>1 \mathrm{GM}\right.$ at $740 \mathrm{~nm}^{42}$ ), we expect 5 to be particularly beneficial for studying subcellular populations of $\mathrm{Na}_{V} \mathrm{~s}$. Successful two-photon uncaging of RuBi-dopamine ${ }^{11}$, which has a smaller $k_{\text {on }}$ and an equivalent $k_{\text {off }}{ }^{53}$ as compared to STX-ea 1 and a lower two-photon cross-sectional efficiency of uncaging than coumarin derivatives, supports this conclusion. While other coumarin-caged tool compounds (e.g., GABA-coumarin) have enjoyed extensive use in two-photon experiments ${ }^{54}, 5$ is the only reagent capable of direct inhibition of action potential initiation. As such, STX-eac 5 offers a valuable complement to photocaged neurotransmitters ${ }^{55}$ that have proven indispensable for investigations of the nervous system.

$\mathrm{Na}_{\mathrm{V}}$ block by uncaged STX-eac $\mathbf{5}$ is spatially precise. We have observed that photo-uncaging is focal, as optical fiber placement must be within $300 \mu \mathrm{m}$ of the callosum to differentiate the two components of the callosal CAP, N1, and N2. Focal uncaging of 5 at a precise location along the callosal tract reduces the amplitude and delays arrival of the $\mathrm{N} 2$ signal but does not alter propagation speed in the region where the APs are measured (i.e., outside of the region of uncaging). Control experiments involving bath application of STX-ea $\mathbf{1}$ show that reduction in action potential amplitude and speed occurs in both $\mathrm{N} 1$ and $\mathrm{N} 2$ under these conditions. Accordingly, these results demonstrate that the effect of uncaging $\mathbf{5}$ is localized, as the measured AP propagation speed would be reduced if $\mathrm{Na}_{\mathrm{V}}$ block was not restricted to the site of light application.

Our data from corpus callosum recordings indicate that electrical transmission in unmyelinated fibers is more susceptible to attenuation than in myelinated fibers. We demonstrate that the faster-conducting corpus callosum signal N1 is largely insensitive to localized delivery of STX-ea 1, whereas the slower signal N2 from unmyelinated fiber is reduced in amplitude and timing. These findings have multiple potential explanations: first, AP conduction in unmyelinated fibers, which tend to be of smaller diameter ${ }^{56}$, may be more susceptible to local blockade. Modeling studies have suggested that $\mathrm{Na}_{\mathrm{V}}$ activity more significantly influences membrane voltage in thinner axon fibers (i.e., unmyelinated $\mathrm{N} 2$ ) than in larger axons (i.e., myelinated $\mathrm{N} 1)^{57}$, thus local block of even a small fraction of $\mathrm{Na}_{\mathrm{V}} \mathrm{s}$ could have a larger relative effect on small, unmyelinated fibers. A second contributing factor may stem from the different mechanisms of AP propagation in the two types of fibers. The corpus callosum contains diverse populations of axons, divided into roughly two groups $^{58}$. Larger diameter axons tend to be myelinated and more reliably transmit action potentials due to saltatory conduction between insulated points (nodes of Ranvier), each expressing a high $\mathrm{Na}_{\mathrm{V}}$ density ${ }^{59}$. Inhibition of a small number of nodes can have a relatively minor effect on AP signaling, as saltatory propagation can apparently bypass or jump across short inactive segments ${ }^{60}$.

We have prepared STX-eac 5 and demonstrated the value of this high-precision tool compound for the localized block of $\mathrm{Na}_{\mathrm{V}} \mathrm{s}$ in dissociated neurons and brain slice. When focally uncaged by a millisecond light pulse, the release of the potent STX derivative, STX-ea 1, results in rapid $\mathrm{Na}_{\mathrm{V}}$ inhibition and impedance of APs. In slice recordings on corpus callosum tissue, focal uncaging of 5 affords specific modulation of APs in slower-conducting, nonmyelinated fibers. Future studies using this reagent may offer insight into the role of unmyelinated fibers in callosal signaling $51,61,62$ or the contributions of such fibers in demyelinating diseases such as multiple sclerosis, among other outstanding questions. We expect the availability of 5 to complement existing technologies for optical control of axonal signaling.

\section{Methods}

\section{Synthesis}

General. All reagents were obtained commercially unless otherwise noted. Organic solutions were concentrated under reduced pressure (ca. 60 Torr) by rotary evaporation. Anhydrous $\mathrm{CH}_{2} \mathrm{Cl}_{2}$ and HPLC-grade $\mathrm{CH}_{3} \mathrm{CN}$ were obtained from commercial suppliers and used as is. $N, N$-dimethylformamide (DMF) was passed through two columns of activated alumina prior to use. Triethylamine was distilled from calcium hydride.

Product purification was accomplished using forced-flow chromatography on Silicycle ultrapure silica gel $(40-63 \mu \mathrm{m})$. Semi-preparative high-performance liquid chromatography (HPLC) was performed on a Varian ProStar model 210. Thinlayer chromatography was performed on EM Science silica gel $60 \mathrm{~F}_{254}$ plates $(250 \mu \mathrm{m})$. Visualization of the developed chromatogram was accomplished by fluorescence quenching. High-resolution mass spectra were obtained from the Vincent Coates Foundation Mass Spectrometry Laboratory at Stanford University Samples were analyzed with LC/ESI-MS by direct injection onto a Waters Acquity UPLC and Thermo Fisher Exactive mass spectrometer scanning $m / z 100-2000$. The LC mobile phase was $100 \%$ methanol and the flow rate was $0.175 \mathrm{~mL} / \mathrm{min}$. Saxitoxin derivatives were quantified by ${ }^{1} \mathrm{H}$ NMR spectroscopy on a Varian Inova $600 \mathrm{MHz}$ NMR instrument using distilled DMF as an internal standard. A relaxation delay (d1) of $20 \mathrm{~s}$ and an acquisition time (at) of $10 \mathrm{~s}$ were used for spectral acquisition. The concentration of the toxin derivative was determined by 

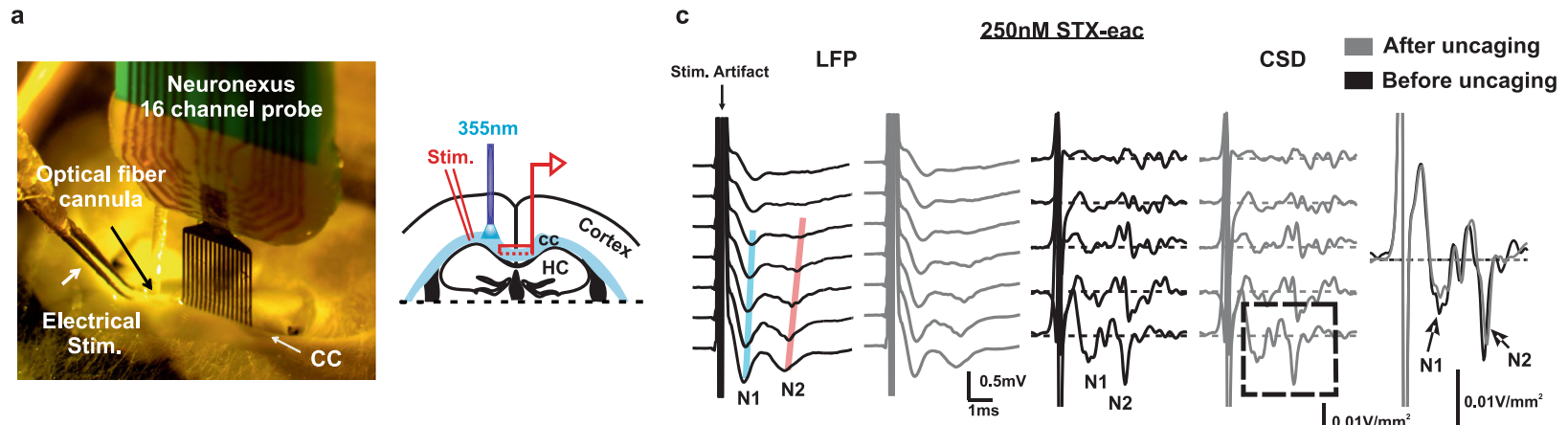

b
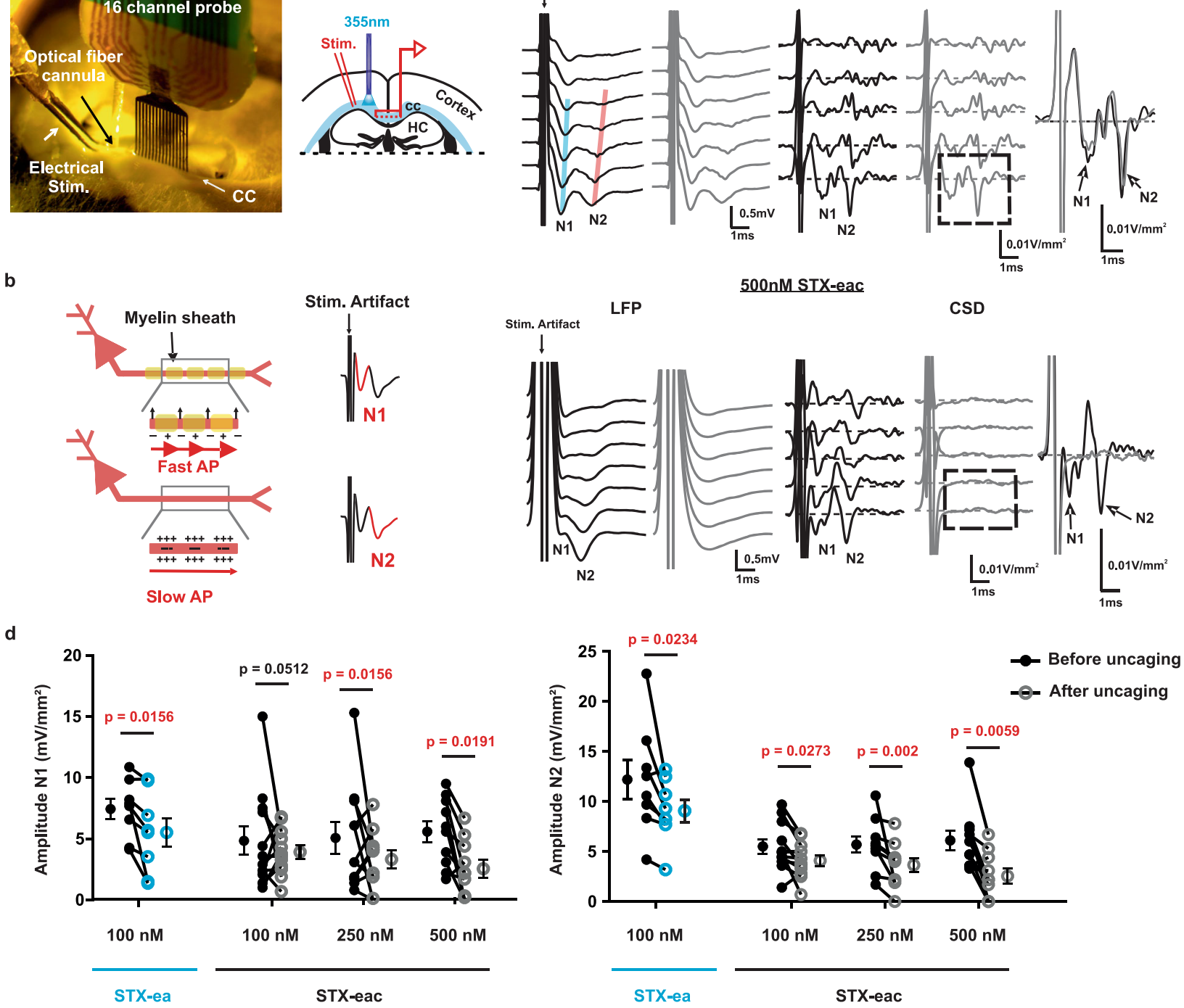

CSD

e
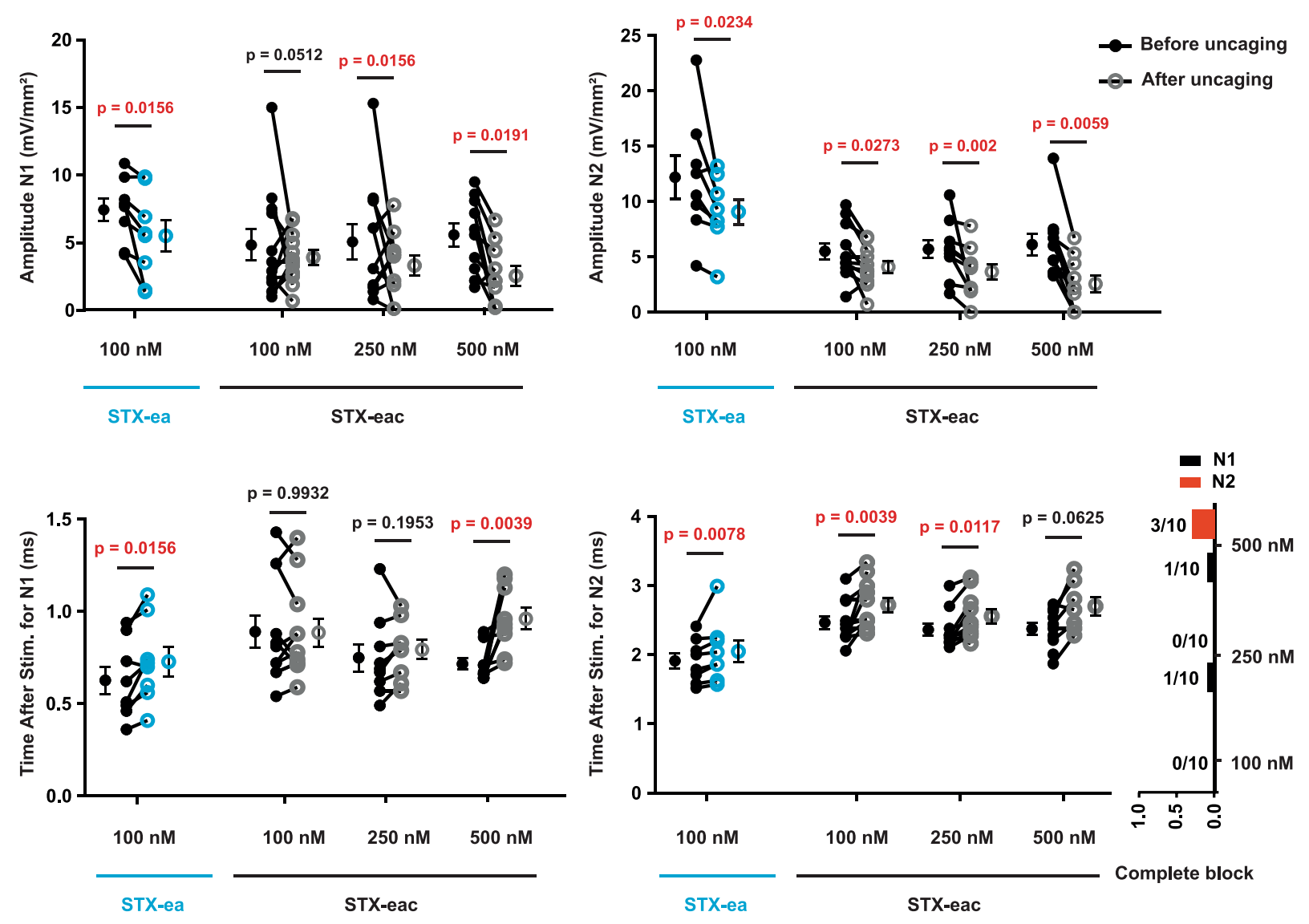

the integration of ${ }^{1} \mathrm{H}$ signals corresponding to the toxin and a fixed concentration of the DMF standard.

disclosed work ${ }^{34}$. N-Hydroxysuccinimide carbonates and photocaged STXs were synthesized as described in the Supplementary Methods.

Compounds. Coumarins 6-bromo-4-(hydroxymethyl)-7-methoxycoumarin (6), 6bromo-7-hydroxy-4-(hydroxymethyl)coumarin (7), and 7-[bis(tert-butoxycarbonylmethyl)-amino]-4-(hydroxymethyl)coumarin (8) were prepared as described in Furuta et al. ${ }^{41}$, Furuta et al. ${ }^{44}$, and Noguchi et al. ${ }^{63}$, respectively. Synthesis of N21-saxitoxin ethylamine (1) was adapted from our previously

Plasmids. Oocyte expression vector pLCT2-rNa 1.3 was a generous gift from Dr. A. L. Goldin (University of California, Irvine, Department of Microbiology \& Molecular Genetics). The full-length cDNA encoding for the alpha subunit of $\mathrm{rNa}_{\mathrm{V}} 1.3$ was excised and inserted into a low-copy modified pcDNA3.1 $(+)$ 
Fig. 5 Uncaging STX-eac 5 differentially affects myelinated vs. unmyelinated callosal fiber transmission. a Experimental design of corpus callosum preparation. On the left, a representative picture of an experiment. On the right, a corresponding schematic representation, $\mathrm{HC}$ stands for the hippocampus; cc for corpus callosum. b Schematic representation of callosal N1 and N2 features. N1 is the fastest component and corresponds mainly to myelinated axon fibers. N2 is slower and corresponds mainly to unmyelinated axon fibers. c Example of LFP and CSD signals for two different concentrations of $\mathbf{5}$ $250 \mathrm{nM}$ (upper panel) and $500 \mathrm{nM}$ (lower panel). Black traces represent signals before uncaging, gray traces represent signals after uncaging by $500 \mathrm{~ms}$ UV pulse light delivery. Only the first seven channels closest to the stimulating electrode are represented. The expanded timescale of the first CSD channel is represented on the right. For $250 \mathrm{nM} \mathrm{5}$, a reduction of amplitude and a delay of the peak time can be observed after uncaging for N2. Only a reduction of amplitude can be observed for N1; peak time was not affected. For 500 nM 5, a loss of N1 and N2 signals can be observed after light delivery. d Scatter plot of the effect of $100 \mathrm{nM}$ bath application of 1 in blue and of the effect of uncaging of 100, 250, and $500 \mathrm{nM} \mathbf{5}$ on N1 (left graph) and N2 (right graph) amplitude. e Scatter plot of the effect $100 \mathrm{nM}$ bath application of $\mathbf{1}$ in blue and of uncaging of 100, 250, and $500 \mathrm{nM} \mathbf{5}$ on the N1 (left) and N2 (middle) peak time. Histograms (on the right) represent the incidence of complete block for N1 (black) and N2 (red) for the three different concentrations of 5, 100, 250, and $500 \mathrm{nM}$. Increases in peak timing were observed with $100 \mathrm{nM} \mathbf{1}$ and $500 \mathrm{nM} 5$ for N1 and with $100 \mathrm{nM} \mathbf{1}, 100 \mathrm{nM}$ and $250 \mathrm{nM} \mathbf{5}$ for N2. Notice that $30 \%$ of the slices have a complete block of $\mathrm{N} 2$ at $500 \mathrm{nM}$, obscuring any potential difference in latency. d, e Two-tailed Wilcoxon test $(n=8,7,5$, and 8 , respectively, for $100 \mathrm{nM} \mathrm{1,100} \mathrm{nM,} 250 \mathrm{nM}$, and $500 \mathrm{nM} \mathrm{5}$ ). $P$ values less than 0.05 are highlighted in red. Each pair of connected dots represents the results of a single slice before (filled circle) and after (open circle) light application. For each condition mean \pm s.e.m. are represented on each side of the connected dots.

vector ${ }^{64}$ by VectorBuilder (Vector ID VB190704-1006vdy). Detailed information about the vector can be retrieved at vectorbuilder.com. Mammalian expression vector pZem228 containing the cDNA coding for the alpha subunit of rat $\mathrm{Na}_{\mathrm{V}}$ 1.4 was a generous gift from Dr. S. R. Levinson (University of Colorado, Department of Physiology and Biophysics). Mammalian expression vector pcDNA3.1 $(+)$ containing the cDNA coding for the alpha subunit of human $\mathrm{Na}_{V} 1.5$ originated from Dr. T. R. Cummins (Indiana University, Department of Biology).

\section{Cell culture}

Chinese hamster ovary (CHO) cells stably expressing rat $\mathrm{Na}_{V}$ 1.2. Stably expressing $\mathrm{Na}_{\mathrm{V}} 1.2 \mathrm{CHO}$ cells were generously provided by Dr. W. A. Catterall (University of Washington, Department of Pharmacology). Cells were grown on 10-cm tissue culture dishes in RPMI 1640 medium with L-glutamine (Thermo Fisher, Waltham, MA) and supplemented with $10 \%$ fetal bovine serum (ATCC, Manassas, VA), $50 \mathrm{U} / \mathrm{mL}$ penicillin-streptomycin (Thermo Fisher, Waltham, MA), and $0.2 \mu \mathrm{g} / \mathrm{mL}$ G418 (Sigma-Aldrich Co., St. Louis, MO). Cells were kept in a $37^{\circ} \mathrm{C}, 5 \%$ carbon dioxide, $96 \%$ relative humidity incubator and passaged approximately every 3 days. Passaging of cells was accomplished by aspiration of media, washing with phosphate-buffered saline, treatment with $1 \mathrm{~mL}$ of trypsin-EDTA $(0.05 \%$ trypsin, Millipore Sigma, Hayward, CA) until full dissociation of cells was observed $(\sim 5 \mathrm{~min})$, and dilution with $4 \mathrm{~mL}$ of growth medium. Cells were routinely passaged at 1 in 20 to 1 in 10 dilution.

Chinese hamster ovary $\mathrm{K} 1$ (CHO-K1) cells transiently expressing $\mathrm{Na}_{\mathrm{V}} \mathrm{S} . \mathrm{CHO}-\mathrm{K} 1$ cells were grown on 10-cm tissue culture dishes in F12-K medium (ATCC, Manassas, VA) and supplemented with 10\% fetal bovine serum (ATCC, Manassas, VA) and $50 \mathrm{U} / \mathrm{mL}$ penicillin-streptomycin (Thermo Fisher, Waltham, MA). Cells were kept in a $37^{\circ} \mathrm{C}, 5 \%$ carbon dioxide, $96 \%$ relative humidity incubator and passaged approximately every 3 days. Passaging of cells was accomplished by aspiration of media, washing with phosphate-buffered saline, treatment with $1 \mathrm{~mL}$ of trypsin-EDTA (0.05\% trypsin, Millipore Sigma, Hayward, CA) until full dissociation of cells was observed $(\sim 5 \mathrm{~min})$, and dilution with $4 \mathrm{~mL}$ of growth medium. Cells were routinely passaged at 1 in 20 to 1 in 10 dilution. Lipofectamine ${ }^{\mathrm{TM}}$ LTX PLUS ${ }^{\mathrm{TM}}$ Reagent was used to accomplish all transient transfections, according to the manufacturer's instructions (Thermo Fisher, Waltham, MA).

Rat embryonic day 18 Sprague Dawley hippocampal neurons. Prior to dissection, 5 $\mathrm{mm}$ diameter, $0.15 \mathrm{~mm}$-thick round glass coverslips (Warner Instruments, Hamden, CT) were coated overnight with $1 \mathrm{mg} / \mathrm{mL}$ poly-D-lysine hydrobromide (PDL, molecular weight 70,000-150,000 Da, Millipore Sigma, Hayward, CA) in $0.1 \mathrm{M}, \mathrm{pH} 8.5$ borate buffer in a $37^{\circ} \mathrm{C}, 5 \%$ carbon dioxide, $96 \%$ relative humidity incubator.

Hippocampi were dissected from embryonic day 18 fetuses into ice-cold Hibernate E (BrainBits, LLC, Springfield, IL) as previously described ${ }^{65}$. Following dissection, cells were dissociated in $2 \mathrm{~mL}$ of trypsin-EDTA for $15 \mathrm{~min}$ in a $37^{\circ} \mathrm{C}$, $5 \%$ carbon dioxide, $96 \%$ relative humidity incubator. Subsequently, trypsinized cells were quenched with $10 \mathrm{~mL}$ of quenching medium (DMEM high glucose (Thermo Fisher, Waltham, MA) supplemented with 15\% fetal bovine serum, $100 \mathrm{U} / \mathrm{mL}$ penicillin-streptomycin, and $1 \mathrm{mM}$ MEM sodium pyruvate (Atlanta biologicals, Flowery Branch, GA)). The tissue was allowed to settle, the supernatant was removed, and the tissue pellet was rinsed twice more with $10 \mathrm{~mL}$ of quenching medium. Cells were then manually dissociated into $2 \mathrm{~mL}$ of plating medium (DMEM supplemented with $10 \% \mathrm{FBS}, 50 \mathrm{U} / \mathrm{mL}$ penicillin-streptomycin, and $1 \mathrm{mM}$ MEM sodium pyruvate) by pipetting with a fire-polished 9" borosilicate glass Pasteur pipet (Fisher Scientific, Waltham, MA).
Cells were plated onto PDL-coated $5 \mathrm{~mm}$ glass coverslips in $35 \mathrm{~mm}$ tissue culture dishes containing $2 \mathrm{~mL}$ of plating medium at a density of 200,000 cells/dish (for voltage-clamp experiments) or 600,000 cells/dish (for current-clamp experiments). After $45 \mathrm{~min}$, coverslips were transferred to new tissue culture dishes containing $2 \mathrm{~mL}$ of maintenance medium (neurobasal supplemented with $1 \times \mathrm{B}-27$ Supplement, $1 \times$ Glutamax, and $50 \mathrm{U} / \mathrm{mL}$ penicillin-streptomycin (Thermo Fisher, Waltham, MA)). Cells were fed every $3-4$ days by changing $50 \%$ of the working medium.

Single-cell electrophysiology. Data were measured using the patch-clamp technique in the whole-cell configuration with an Axon Axopatch 200B amplifier (Molecular Devices, San Jose, CA). The output of the patch-clamp amplifier was filtered with a built-in lowpass, four-pole Bessel filter having a cutoff frequency of $5 \mathrm{kHz}$ for voltage-clamp recordings or $10 \mathrm{kHz}$ for current-clamp recordings, and sampled at $100 \mathrm{kHz}$. Pulse stimulation and data acquisition used Molecular Devices Digidata $1322 \mathrm{~A}$ or $1550 \mathrm{~B}$ controlled with pCLAMP software version 10.4 or 11.1, respectively (Molecular Devices, San Jose, CA).

Borosilicate glass micropipettes (Sutter Instruments, Novato, CA) were firepolished to a tip diameter yielding resistance of $1.3-5.5 \mathrm{M} \Omega$, for $\mathrm{Na}_{\mathrm{V}} 1.2 \mathrm{CHO}$ cells, or 3.0-9.0 M $\Omega$, for E18 hippocampal neurons, in the working solutions.

Voltage-clamp recordings. For $\mathrm{Na}_{\mathrm{V}} 1.2 \mathrm{CHO}$ and $\mathrm{CHO}-\mathrm{K} 1$ cells, the internal solution was composed of $40 \mathrm{mM} \mathrm{NaF}, 1 \mathrm{mM}$ EDTA, $20 \mathrm{mM}$ HEPES, and $125 \mathrm{mM}$ $\mathrm{CsCl}$ ( $\mathrm{pH} 7.4$ with $\mathrm{CsOH}$ ); the external solution comprised $160 \mathrm{mM} \mathrm{NaCl}, 2 \mathrm{mM}$ $\mathrm{CaCl}_{2}$, and $20 \mathrm{mM}$ HEPES (pH 7.4 with $\mathrm{CsOH}$ ). For E18, DIV 6-8 hippocampal neurons, the internal solution was composed of $114.5 \mathrm{mM}$ gluconic acid, $114.5 \mathrm{mM}$ $\mathrm{CsOH}, 2 \mathrm{mM} \mathrm{NaCl}, 8 \mathrm{mM} \mathrm{CsCl}, 10 \mathrm{mM}$ MOPS, $4 \mathrm{mM}$ EGTA, $4 \mathrm{mM}$ MgATP, and $0.3 \mathrm{mM} \mathrm{Na}_{2} \mathrm{GTP}$ ( $\mathrm{pH} 7.3$ with CsOH, $240 \mathrm{mOsm}$ with glucose), while the external solution was Hibernate E low fluorescence (BrainBits, LLC, Springfield, IL).

Currents were elicited by $10 \mathrm{~ms}$ step depolarizations from a holding potential $\left(-100 \mathrm{mV}\right.$ for $\mathrm{Na}_{\mathrm{V}} 1.2 \mathrm{CHO}$ and CHO-K1 cells expressing $\mathrm{Na}_{\mathrm{V}} 1.4,-120 \mathrm{mV}$ for CHO-K1 cells expressing $\mathrm{Na}_{\mathrm{V}} 1.3$ or 1.5 , or $-80 \mathrm{mV}$ for E18 hippocampal neurons) to $0 \mathrm{mV}$ at a rate of $0.5 \mathrm{~Hz}$ (unless otherwise noted). Leak currents were subtracted using a standard $\mathrm{P} / 4$ protocol of the same polarity. Series resistance was compensated at $80-95 \%$ with a $\tau_{\text {lag }}$ of 20 or $35 \mathrm{~ms}$ for $\mathrm{Na}_{\mathrm{V}} 1.2 \mathrm{CHO}$ and CHO-K1 cells or E18 hippocampal neurons, respectively. All measurements were recorded at room temperature $\left(20-25^{\circ} \mathrm{C}\right)$. Data were normalized to control currents, plotted against toxin concentration, and analyzed using Prism 8 (GraphPad Software, LLC). Data were fit to concentration-response curves to obtain $\mathrm{IC}_{50}$ values and expressed as mean \pm s.e.m. The number of observations $(n)$ was $\geq 5$ for all reported data unless otherwise noted. For $\mathrm{IC}_{50}$ measurements, cells were used if they exhibited currents $>1 \mathrm{nA}$ upon depolarization, and $\mathrm{I} / \mathrm{I}_{0}$ was within $10 \%$ of the initial current upon toxin washout.

Current-clamp recordings. Data were collected on DIV 9-13 hippocampal neurons firing action potential trains with frequencies greater than $5 \mathrm{~Hz}$. The internal solution was composed of $130 \mathrm{mM} \mathrm{CH}_{3} \mathrm{SO}_{3}{ }^{-} \mathrm{K}^{+}, 8 \mathrm{mM} \mathrm{NaCl}, 10 \mathrm{mM}$ HEPES, $10 \mathrm{mM} \mathrm{Na}_{2}$ phosphocreatine, $3 \mathrm{mM}$-ascorbic acid, $4 \mathrm{mM} \mathrm{MgATP}$, and $0.4 \mathrm{mM} \mathrm{Na}_{2} \mathrm{GTP}$ (pH 7.4 with $\mathrm{KOH}, 305 \mathrm{mOsm}$ with glucose); the external solution comprised Hibernate E low fluorescence adjusted to $310 \mathrm{mOsm}$ with $40 \mathrm{mM} \mathrm{NaCl}$.

Action potentials were elicited by four $500 \mathrm{~ms}$ current injections of $50-150 \mathrm{pA}$ at a rate of $0.25 \mathrm{~Hz}$. Series resistance was typically compensated at $90-95 \%$ with a $\tau_{\text {lag }}$ of $35 \mathrm{~ms}$. All measurements were recorded at room temperature $\left(20-25^{\circ} \mathrm{C}\right)$. Data were analyzed using Clampfit (Molecular Devices, San Jose, CA). The number of observations ( $n$ ) was $\geq 5$ for all reported data. 
UV laser (355 nm). A pulsed 355nm UV laser beam (DPSS Lasers, Model 3501100) was directed through a $200 \mu \mathrm{m}$ core optical fiber to a $200 \mu \mathrm{m}$ core, $0.22 \mathrm{NA}$ fiber-optic cannula (Thorlabs, Newton, NJ) to the clamped cell. Unless otherwise noted, photolysis was induced by $5 \mathrm{~ms}, 130 \mathrm{~mW}$ UV pulses activated immediately prior to the depolarization (or current injection) step.

Extracellular multielectrode recordings. Extracellular recordings were obtained with neocortical coronal $400 \mu \mathrm{m}$-thick slices obtained from young $(\sim \mathrm{P} 35)$ male and female wild-type mice from the $\mathrm{C} 3 \mathrm{HeB} / \mathrm{FeJ}-\mathrm{Scn} 8 \mathrm{amed} / \mathrm{J}$ strain. Slices containing the midline crossing segments of the corpus callosum (Bregma 0.4 to -1 ) were saved, which represents three slices per brain. Recordings were performed in a humidified oxygenated interface chamber at $34^{\circ} \mathrm{C}$ and perfused at a rate of $2 \mathrm{ml} /$ min with oxygenated ACSF. The ACSF contained: $10 \mathrm{mM}$ glucose, $26 \mathrm{mM}$ $\mathrm{NaHCO}_{3}, 2.5 \mathrm{mM} \mathrm{KCl}, 1.25 \mathrm{mM} \mathrm{NaHPO}_{4}, 1 \mathrm{mM} \mathrm{MgSO} 4,2 \mathrm{mM} \mathrm{CaCl}_{2}$, and $126 \mathrm{mM} \mathrm{NaCl}(298 \mathrm{mOsm})$.

A linear silicon multichannel probe (16 channels, $100 \mu \mathrm{m}$ interelectrode spacing, NeuroNexus Technologies) was placed in the midline of the corpus callosum. A bipolar tungsten microelectrode (each wire, $50-100 \mathrm{k} \Omega$, FHC) was positioned in the corpus callosum in one hemisphere at $\sim 1 \mathrm{~mm}$ from the closest channel of the recording electrode, angled to ensure that both contacts were within the boundaries of the callosum. Both electrodes were initially lowered to $\sim 200 \mu \mathrm{m}$ slice depth, and fine adjustments were made to optimize the signal amplitude of the evoked compound action potential (CAP), representing the summed activity of callosal fibers $^{44}$. Biphasic electrical stimuli $( \pm 400 \mu \mathrm{A}, 0.2 \mathrm{~ms}$ each phase) were delivered every $10 \mathrm{~s}$ to elicit the callosal CAP response. This evoked response has previously been characterized by a faster component generated mainly by fast-conducting myelinated axons (N1), and a slower component reflecting mainly slower unmyelinated axons $(\mathrm{N} 2)^{66}$.

A laser pulse of $500 \mathrm{~ms}, 40 \mathrm{~mW}, 355 \mathrm{~nm}$ UV (DPSS Lasers, Model 3501-100) was directed through a $200 \mu \mathrm{m}$ core optical fiber to a $0.22 \mathrm{NA}$ cannula (Thorlabs, Newton, NJ) placed along the callosum between the recording and stimulating electrode to photo-uncage 5. Ultraviolet light intensity was optimized for each type of experiment and each type of tissue. To observe an artifact-free biological effect of the uncaged 5 in $400 \mu \mathrm{m}$ thick slices containing the corpus callosum, we applied a lower, non-damaging intensity $(40 \mathrm{~mW})$ of UV light. Under these conditions, the duration of uncaging UV light stimulation needed to be $\geq 500 \mathrm{~ms}$. In each set of experiments, we routinely evaluated the effects of the light stimulus in the absence of $\mathbf{5}$, to rule out nonspecific effects. Three concentrations of 5 (100, 250, and 500 $\mathrm{nM}$ ) were tested on callosal CAP N1 and N2 in three different mice groups (respectively, $n=7, n=5$, and $n=8$ ).

The following protocol was performed on each slice: application of ACSF for 5 min, delivery of a UV light pulse, 5 min of ACSF, application of STX-eac for 10 min, delivery of a UV light pulse, $5 \mathrm{~min}$ of uncaged version of STX-eac, $10 \mathrm{~min}$ wash-off with ACSF.

For the bath application experiment, $100 \mathrm{nM} 1$ was used. After $5 \mathrm{~min}$ of ACSF application, callosal responses were recorded to obtain a baseline. Then, 1 was applied in the bath for $10 \mathrm{~min}$ and 15 callosal responses were elicited and recorded. Wash-off with ACSF was next performed over $10 \mathrm{~min}$.

Evoked callosal CAP field potentials elicited by electrical stimulations were digitized at $25 \mathrm{kHz}$, and stored using an RZ5D processor multichannel workstation (Tucker-Davis Technologies). Signals were band-pass filtered between $1 \mathrm{~Hz}$ and $3 \mathrm{kHz}$. To obtain a more reliable index of the location, direction, and magnitude of currents underlying synchronous network activity, we derived the current-source density (CSD) from raw LFP signals ${ }^{67}$. Assuming a uniform extracellular resistivity, the CSD can be estimated as the second spatial derivative of the LFP. CSD peak amplitudes and times of $\mathrm{N} 1$ and $\mathrm{N} 2$ components of the closest channel to the stimulating electrode were quantified using trial-averaged responses (ten trials per condition).

Ethics oversight. All animal care and dissection procedures were approved by the Stanford Administrative Panel on Laboratory Animal Care (APLAC).

Reporting summary. Further information on research design is available in the Nature Research Reporting Summary linked to this article.

\section{Data availability}

The datasets generated in the current study are available from the corresponding authors on request. All synthetic characterization data generated during this study are included in the supplemental information files. Source data are provided with this paper.

\section{Code availability}

For callosal experiment analysis, data were exported from OpenDeveloper (Tucker-Davis Technologies, Inc) to MATLAB using the provided TDT2mat.m code. A custom MATLAB code was then used to obtain CSD measurements from LFP data. The formula is as follows: $\operatorname{csd}=-\operatorname{diff}(\operatorname{diff}($ data, 1, chan $), 1$, chan $) . / s p 2$ with data $=$ LFP data obtained from the TDT2mat.m extraction, chan $=2$, sp2 (probe spacing) $=0.1$ (i.e., $100 \mu \mathrm{m}$ ).
Received: 3 December 2020; Accepted: 9 June 2021; Published online: 07 July 2021

\section{References}

1. Barltrop, J. \& Schofield, P. Photosensitive protecting groups. Tetrahedron Lett. 3, 697-699 (1962)

2. Liu, J. et al. Genetically encoding photocaged quinone methide to multitarget protein residues covalently in vivo. J. Am. Chem. Soc. 141, 9458-9462 (2019).

3. Aonbangkhen, C., Zhang, H., Wu, D. Z., Lampson, M. A. \& Chenoweth, D. M. Reversible control of protein localization in living cells using a photocagedphotocleavable chemical dimerizer. J. Am. Chem. Soc. 140, 11926-11930 (2018).

4. So, W. H., Wong, C. T. \& Xia, J. Peptide photocaging: a brief account of the chemistry and biological applications. Chin. Chem. Lett. 29, 1058-1062 (2018).

5. Sansalone, L. et al. Photopotentiation of the $\mathrm{GABA}_{\mathrm{A}}$ receptor with caged diazepam. Proc. Natl Acad. Sci. USA 116, 21176-21184 (2019).

6. Gautier, A., Deiters, A. \& Chin, J. W. Light-activated kinases enable temporal dissection of signaling networks in living cells. J. Am. Chem. Soc. 133, 2124-2127 (2011).

7. Oosenbrug, T., Graaff, M. J. V. D., Ressing, M. E. \& Kasteren, S. I. V. Chemical tools for studying TLR signaling dynamics. Cell Chem. Bio 24, 801-812 (2017).

8. Rothman, S. M., Perry, G., Yang, X.-F., Hyrc, K. \& Schmidt, B. F. Optical suppression of seizure-like activity with an LED. Epilepsy Res. 74, 201-209 (2007).

9. Shembekar, V. R., Chen, Y., Carpenter, B. K. \& Hess, G. P. A protecting group for carboxylic acids that can be photolyzed by visible light. Biochem 44, 7107-7114 (2005)

10. Kumar, P., Shukhman, D. \& Laughlin, S. T. A photocaged, cyclopropenecontaining analog of the amino acid neurotransmitter glutamate. Tetrahedron Lett. 57, 5750-5752 (2016).

11. Araya, R., Andino-Pavlovsky, V., Yuste, R. \& Etchenique, R. Two-photon optical interrogation of individual dendritic spines with caged dopamine. ACS Chem. Neurosci. 4, 1163-1167 (2013)

12. Cabrera, R. et al. A visible-light-sensitive caged serotonin. ACS Chem. Neurosci. 8, 1036-1042 (2017)

13. Banghart, M. R. \& Sabatini, B. L. Photoactivatable neuropeptides for spatiotemporally precise delivery of opioids in neural tissue. Neuron 73, 249-259 (2012).

14. Priestman, M. A., Sun, L. \& Lawrence, D. S. Dual wavelength photoactivation of cAMP- and CGMP-dependent protein kinase signaling pathways. ACS Chem. Bio 6, 377-384 (2011).

15. Gaur, P., Kucherak, O. A., Ermakova, Y. G., Shvadchak, V. V. \& Yushchenko, D. A. Nitrobenzyl-based fluorescent photocages for spatial and temporal control of signaling lipids in cells. Chem. Commun. 55, 12288-12291 (2019).

16. Zhao, M. et al. Optical triggered seizures using a caged 4 -aminopyridine. Front. Neurosci. 9, 1-10 (2015).

17. Rowan, M. J. M., Tranquil, E. \& Christie, J. M. Distinct $\mathrm{K}_{\mathrm{V}}$ channel subtypes contribute to differences in spike signaling properties in the axon initial segment and presynaptic boutons of cerebellar interneurons. J. Neurosci. 34, 6611-6623 (2014)

18. Rowan, M. J. M., DelCanto, G., Yu, J. J., Kamasawa, N. \& Christie, J. M Synapse-level determination of action potential duration by $\mathrm{K}^{+}$channel clustering in axons. Neuron 91, 370-383 (2016).

19. Heckman, L. M. et al. Design and synthesis of a calcium-sensitive photocage. Angew. Chem. Int. Ed. 55, 8363-8366 (2016).

20. Sternson, S. M. \& Roth, B. L. Chemogenetic tools to interrogate brain functions. Annu. Rev. Neurosci. 37, 387-407 (2014).

21. Fenno, L., Yizhar, O. \& Deisseroth, K. The development and application of optogenetics. Annu. Rev. Neurosci. 34, 389-412 (2011).

22. Roth, B. L. DREADDs for neuroscientists. Neuron 89, 683-694 (2016).

23. Tischer, D. \& Weiner, O. D. Illuminating cell signalling with optogenetic tools. Nat. Rev. Mol. Cell. Biol. 15, 551-558 (2014).

24. Nikolic, K., Jarvis, S., Grossman, N. \& Schultz, S. Computational models of optogenetic tools for controlling neural circuits with light. Conf. Proc. Ieee. Eng. Med. Biol. Soc. 2013, 5934-5937 (2013).

25. Sorokin, J. M. et al. Bidirectional control of generalized epilepsy networks via rapid real-time switching of firing mode. Neuron 93, 194-210 (2017).

26. Rush, A. M., Cummins, T. R. \& Waxman, S. G. Multiple sodium channels and their roles in electrogenesis within dorsal root ganglion neurons. J. Physiol. 579, 1-14 (2007).

27. Debanne, D., Daoudal, G., Sourdet, V. \& Russier, M. Brain plasticity and ion channels. J. Physiol. Paris 97, 403-414 (2003).

28. Bean, B. P. The action potential in mammalian central neurons. Nat. Rev. Neurosci. 8, 451-465 (2007).

29. Carter, B. C. \& Bean, B. P. Sodium entry during action potentials of mammalian neurons: incomplete inactivation and reduced metabolic efficiency in fast-spiking neurons. Neuron 64, 898-909 (2009). 
30. Carter, B. C. \& Bean, B. P. Incomplete inactivation and rapid recovery of voltage-dependent sodium channels during high-frequency firing in cerebellar Purkinje neurons. J. Neurophysiol. 105, 860-871 (2011).

31. Turner, R. W., Meyers, D. E. \& Barker, J. L. Localization of tetrodotoxinsensitive field potentials of CA1 pyramidal cells in the rat hippocampus. $J$. Neurophysiol. 62, 1375-1387 (1989).

32. Trenholm, S. et al. Nonlinear dendritic integration of electrical and chemical synaptic inputs drives fine-scale correlations. Nat. Neurosci. 17, 1759-1766 (2014).

33. Finkelstein, D. Saxitoxin-derived Probes for Labeling Voltage-gated Sodium Channels. PhD Thesis, Stanford University (2016).

34. Mulcahy, J. V. \& Du Bois, J. A stereoselective synthesis of (+)-gonyautoxin 3. J. Am. Chem. Soc. 130, 12630-12631 (2008).

35. Klán, P. et al. Photoremovable protecting groups in chemistry and biology: reaction mechanisms and efficacy. Chem. Rev. 113, 119-191 (2012).

36. Kotzur, N., Benoit, B., Beyermann, M. \& Hagen, V. Wavelength-selective photoactivatable protecting groups for thiols. J. Am. Chem. Soc. 131 , 16927-16931 (2009).

37. Givens, R. S., Rubina, M. \& Wirz, J. Applications of p-hydroxyphenacyl (pHP) and coumarin-4-ylmethyl photoremovable protecting groups. Photochem. Photobiol. Sci. 11, 472 (2012).

38. Shen, H., Liu, D., Wu, K., Lei, J. \& Yan, N. Structures of human Nav1.7 channel in complex with auxiliary subunits and animal toxins. Science 363, 1303-1308 (2019).

39. Thomas-Tran, R. \& Du Bois, J. Mutant cycle analysis with modified saxitoxins reveals specific interactions critical to attaining high-affinity inhibition of $\mathrm{hNa}_{\mathrm{V}}$ 1.7. Proc. Natl Acad. Sci. USA 113, 5856-5861 (2016).

40. Furuta, T. et al. Bhc-cNMPs as either water-soluble or membrane-permeant photoreleasable cyclic nucleotides for both one- and two-photon excitation. ChemBioChem 5, 1119-1128 (2004).

41. Furuta, T. et al. Brominated 7-hydroxycoumarin-4-ylmethyls: photolabile protecting groups with biologically useful cross-sections for two photon photolysis. Proc. Natl Acad. Sci. USA 96, 1193-1200 (1999).

42. Suzuki, A. Z. et al. Coumarin-4-ylmethoxycarbonyls as phototriggers for alcohols and phenols. Org. Lett. 5, 4867-4870 (2003).

43. Senda, N., Momotake, A. \& Arai, T. Synthesis and photocleavage of 7-[ $\{$ bis (carboxymethyl)-amino\} coumarin-4-yl]methyl-caged neurotransmitters. $B$. Chem. Soc. Jpn 80, 2384-2388 (2007).

44. Furuta, T. et al. Phototriggers for nucleobases with improved photochemical properties. J. Am. Chem. Soc. 9, 4717-4720 (2007).

45. Hagen, V. et al. Coumarinylmethyl esters for ultrafast release of high concentrations of cyclic nucleotides upon one- and two-photon photolysis. Angew. Chem. Int. Ed. 44, 7887-7891 (2005).

46. Guo, F. et al. The up-regulation of voltage-gated sodium channel subtypes coincides with an increased sodium current in hippocampal neuronal culture model. Neurochem. Int. 62, 287-295 (2013).

47. Madeja, M. Do neurons have a reserve of sodium channels for the generation of action potentials? A study on acutely isolated CA1 neurons from the guinea-pig hippocampus. Eur. J. Neurosci. 12, 1-7 (2000)

48. Hu, H. \& Jonas, P. A supercritical density of $\mathrm{Na}^{+}$channels ensures fast signaling in GABAergic interneuron axons. Nat. Neurosci. 17, 686-693 (2014).

49. Preston, R. J., Waxman, S. G. \& Kocsis, J. D. Effects of 4-aminopyridine on rapidly and slowly conducting axons of rat corpus callosum. Exp. Neurol. 79, 808-820 (1983).

50. Crawford, D. K., Mangiardi, M. \& Tiwari-Woodruff, S. K. Assaying the functional effects of demyelination and remyelination: revisiting field potential recordings. J. Neurosci. Methods 182, 25-33 (2009).

51. Reeves, T. M., Phillips, L. L. \& Povlishock, J. T. Myelinated and unmyelinated axons of the corpus callosum differ in vulnerability and functional recovery following traumatic brain injury. Exp. Neurol. 196, 126-137 (2005).

52. Payandeh, J. \& Hackos, D. H. Selective ligands and drug discovery targeting the voltage-gated sodium channel Nav1.7. Handb. Exp. Pharmacol. 246, 271-306 (2018).

53. Hunger, L., Kumar, A. \& Schmidt, R. Abundance compensates kinetics: similar effect of dopamine signals on $\mathrm{d} 1$ and $\mathrm{d} 2$ receptor populations. $J$. Neurosci. 40, 2868-2881 (2020).

54. Kanemoto, Y. et al. Spatial distributions of GABA receptors and local inhibition of $\mathrm{Ca} 2$ transients studied with GABA uncaging in the dendrites of CA1 pyramidal neurons. PLoS ONE 6, e22652 (2011).

55. Ellis-Davies, G. C. R. Two-photon uncaging of glutamate. Front. Synaptic Neurosci. 10, 1-13 (2019).

56. Reeves, T. M., Smith, T. L., Williamson, J. C. \& Phillips, L. L. Unmyelinated axons show selective rostrocaudal pathology in the corpus callosum after traumatic brain injury. J. Neuropathol. Exp. Neurol. 71, 198-210 (2012).

57. Faisal, A. A., White, J. A. \& Laughlin, S. B. Ion-channel noise places limits on the miniaturization of the brain's wiring. Curr. Biol. 15, 1143-1149 (2005).

58. Seggie, J. \& Berry, M. Ontogeny of interhemispheric evoked potentials in the rat: significance of myelination of the corpus callosum. Exp. Neurol. 35, 215-232 (1972).

59. Boullerne, A. I. The history of myelin. Exp. Neurol. 283, 431-435 (2016).
60. Tasaki, I. The electro-saltatory transmission of the nerve impulse and the effect of narcosis upon the nerve fiber. Am. J. Physiol. 127, 211-227 (1939)

61. Sampaio-Baptista, C. \& Johansen-Berg, H. White matter plasticity in the adult brain. Neuron 96, 1239-1251 (2017).

62. Williamson, J. M. \& Lyons, D. A. Myelin dynamics throughout life: an everchanging landscape? Front. Cell. Neurosci. 12, 424 (2018).

63. Noguchi, M. et al. Development of novel water-soluble photocleavable protective group and its application for design of photoresponsive paclitaxel prodrugs. Bioorg. Med. Chem. 16, 5389-5397 (2008).

64. Klugbauer, N., Lacinova, L., Flockerzi, V. \& Hofmann, F. Structure and functional expression of a new member of the tetrodotoxin-sensitive voltageactivated sodium channel family from human neuroendocrine cells. $E M B O J$. 14, 1084-1090 (1995).

65. Fath, T. Primary support cultures of hippocampal and substantia nigra neurons. Nat. Protoc. 4, 78-85 (2009).

66. Colley, B. S., Phillips, L. \& Reeves, T. M. The effects of cyclosporin-A on axonal conduction deficits following traumatic brain injury in adult rats. Exp. Neurol. 224, 241-251 (2010).

67. Freeman, J. A. \& Nicholson, C. Experimental optimization of current sourcedensity technique for anuran cerebellum. J. Neurophysiol. 38, 369-382 (1975).

\section{Acknowledgements}

This work was supported by a National Institutes of Health grant R21NS107003 to J.R. H. and J.D. and in part by R01 NS045684A1 and R01 GM117263 (J.D.). C.D.M. was supported by the National Institutes of Health, National Institute of Neurological Disorders and Stroke K99NS104215. A.V.E. was supported by the Stanford Center for Molecular Analysis and Design (CMAD) as well as a Stanford Interdisciplinary Graduate Fellowship (SIGF) through the Stanford Bio-X Interdisciplinary Biosciences Institute. A.L.H. was supported by a Stanford Chemistry Undergraduate Summer Research Fellowship.

\section{Author contributions}

A.V.E., C.D.M., J.R.H., and J.D. conceived the project. A.V.E. and J.D. designed photocaged STXs. A.V.E. and A.L.H. synthesized all photocaged STXs and chemical intermediates. A.V.E. collected potency and uncaging data against $\mathrm{Na}_{\mathrm{V}} 1.2 \mathrm{CHO}$ cells, $\mathrm{CHO}$ K1 cells, and singly dissociated hippocampal neurons. G.D. performed all slice physiology experiments. All authors contributed to data analysis and the writing of the manuscript.

\section{Competing interests}

J.D. is a cofounder and holds equity shares in SiteOne Therapeutics, Inc., a startup company interested in developing subtype-selective $\mathrm{Na}_{\mathrm{V}}$ modulators. The remaining authors declare no competing interests.

\section{Additional information}

Supplementary information The online version contains supplementary material available at https://doi.org/10.1038/s41467-021-24392-2.

Correspondence and requests for materials should be addressed to J.R.H. or J.D.

Peer review information Nature Communications thanks Bruce Bean and the other, anonymous, reviewer(s) for their contribution to the peer review of this work.

Reprints and permission information is available at http://www.nature.com/reprints

Publisher's note Springer Nature remains neutral with regard to jurisdictional claims in published maps and institutional affiliations.

Open Access This article is licensed under a Creative Commons Attribution 4.0 International License, which permits use, sharing, adaptation, distribution and reproduction in any medium or format, as long as you give appropriate credit to the original author(s) and the source, provide a link to the Creative Commons license, and indicate if changes were made. The images or other third party material in this article are included in the article's Creative Commons license, unless indicated otherwise in a credit line to the material. If material is not included in the article's Creative Commons license and your intended use is not permitted by statutory regulation or exceeds the permitted use, you will need to obtain permission directly from the copyright holder. To view a copy of this license, visit http://creativecommons.org/ licenses/by/4.0/

(C) The Author(s) 2021, corrected publication 2022 